\title{
Residual stress reduction of LPBF-processed CM247LC samples via multi laser beam strategies
}

\author{
Marcel Gerstgrasser ${ }^{1} \cdot$ Michael Cloots $^{2} \cdot$ Josef Stirnimann ${ }^{3} \cdot$ Konrad Wegener $^{1,3}$
}

Received: 2 January 2021 / Accepted: 12 April 2021 / Published online: 30 April 2021

(C) The Author(s) 2021

\begin{abstract}
Based on SLM parameters from previous works, which guarantee fully dense and crack free CM247LC samples, multi laser beam strategies have been pursued to reduce residual stresses or rather distortion during LPBF processing. By using a second post heating and non-melting laser source with a defocused laser beam and lateral offset, cantilever distortion is reduced more than $7.5 \%$, compared to the reference. Based on pre-tests with 9 different offset parameters, the optimum offset has been identified. Also, an upper limit for the laser power of $65 \mathrm{~W}$ is identified for the second heat laser beam with a spot diameter of $380 \mu \mathrm{m}$, to avoid re-melting and creating new defects. A theoretical "two bar model," to explain the residual stress behavior and reduction with multi laser beam offset strategy during the LPBF process, is presented. Furthermore, re-melting cracks, defects, and microstructure are analyzed in conjunction with the second defocused offset laser, in case of a $200 \mathrm{~W}$ laser power, an increased scan speed of 1300 $\mathrm{mms} / \mathrm{s}$, and a reduced hatch distance. Secondary electron signal (SE) images of re-melting cracks are analyzed and compared to SE-image of hot cracks (solidification cracks). Based on electron backscatter diffraction (EBSD), the results of the microstructure from the last mentioned multi laser beam approach, which creates re-melting cracks, are presented and analyzed.
\end{abstract}

Keywords CM247LC $\cdot$ Laser powder bed fusion · Selective laser melting $\cdot$ Multi laser beam offset $\cdot$ Residual stress reduction · Re-melting cracks

\section{Introduction}

Considering a standard powder bed fusion (PBF) process, a thin layer of metal powder is deposited onto a part-build area or platform [1]. The laser beam, which is guided by galvano mirrors, scans over the powder bed to form solidified layers, whereas the powder in other areas remains loose. Subsequently, the next powder layer is deposited after the build platform has moved onelayer thickness downwards. The mentioned procedure is repeated, until the final work piece is completely built.

Marcel Gerstgrasser

gerstgrasser@iwf.mavt.ethz.ch; http://www.iwf.mavt.ethz.ch

1 Institute of Machine Tools and Manufacturing, ETH Zurich, Leonhardstrasse 21, 8092 Zurich, Switzerland

2 IRPD AG, Lerchenfeldstrasse 3, 9014 St. Gallen, Switzerland

3 Inspire AG, Technoparkstrasse 1, 8005 Zurich, Switzerland
Nickel-base alloy CM247LC is usually used in the aviation field for high-pressure turbine vanes (HPTV), highpressure and low-pressure turbine blades (HPTB and LPTB, respectively) [2]. Considering the high costs of casting and tooling, especially in case of the cooling systems within the blades with their complex geometry, the aerospace manufacturers have veered towards the laser powder bed fusion (LPBF) technology or selective laser melting (SLM), which eliminates those expensive processes, as reported in [3].

In general, large zones of tensile stresses can be found at the upper zone of prismatic LPBF parts and at the lower part of the used base plate, whereas the upper part of the base plate remains under compressive stresses, before part removal [4]. At the surface of the LPBF-processed part, tensile stresses reach their maximum. In the last layer, stress values reach the same values as the yield stress of the material itself. To reduce residual stresses in LPBF parts and the corresponding distortion, four main strategies can be pursued: tuning the chemical composition, adjusting scan strategies, SLM process and laser parameters, using add-on processes (e.g., powder bed heating and laser shock peening), or post-processes. 
Often, two and more strategies are combined to achieve a greater reduction in distortion.

In [5], LPBF of pre-alloyed AlSi12 powder and in situ alloyed $\mathrm{Al}+\mathrm{Si} 12$ at a powder bed pre-heat temperature of $380{ }^{\circ} \mathrm{C}$ was compared and while the in situ alloyed powder worked well, powder depositing of pre-alloyed AlSil2 was not possible during LPBF due to agglomeration. Furthermore, with the mixed powder, a stress reduced state throughout the build was created with powder bed preheating. Similarly, according to [6], in situ alloying of Al339 (Al-Si-Cu-Mg-Ni), based on pre-alloyed batch blends AlMg and $\mathrm{SiCuNi}$, does not develop significant residual stresses within the process and allows building parts without anchors or supports when powder bed pre-heating is applied.

Island scan strategies with $2 \times 2,3 \times 3,5 \times 5$, and $7 \times 7$ $\mathrm{mm}^{2}$ sizes for LPBF-processed IN718 alloy samples result in different residual stress states, as demonstrated in [7]. Considering also the relative density as an additional requirement, the scan strategy with $5 \times 5 \mathrm{~mm}^{2}$ size generates the lowest residual stresses. The comparison of different laser scan strategies in [8], continuous (back-and-forth hatching pattern along the entire dimension of the part), and island strategy, for LPBF-processed IN718, clearly shows the highest distortion in the samples with the island strategy, followed by continuous. The results in [9] demonstrate for LPBF of Ti6Al4V that the $90^{\circ}$ alternating bi-directional scanning strategy yields less residual stresses during LPBF, compared to chessboard scanning. The residual stresses also increase with increasing chessboard block size. Similar investigations about bi-directional and chessboard scanning are made with LPBF-processed nickel-base alloy 718 in the study of [10]. The bi-directional raster scanning tends to have lower residual stresses compared to the chessboard approach. Generally, the distortion of LPBF-processed cantilevers after lifting off from the platform increases with increasing relative density, as observed for hot working steel 1.2709 in [11]. Furthermore, for this material, a correlation between internal stresses or upon their release distortions and the scan speed was recognized. In case of austenitic stainless steel 1.4404 and Invar 36, [12, 13] reported an increase of residual stresses and distortions with increasing energy density, for all tested scan speeds. Contrary, for LPBF-processed Ti6Al4V samples, the distortions decreased with increased energy density according to [14]. Further information about the development of residual stresses or warp and their reduction via choice of scan strategies or process parameters can be found in [15].

Preheating to temperatures of $550{ }^{\circ} \mathrm{C}$ to $570{ }^{\circ} \mathrm{C}$ has the main effect on distortion reduction and significantly reduces residual stresses in case of LPBF-processed Ti6A14V but leads to fast powder degradation, as explained in detail in $[14,16]$. In case of LPBF-processed AlSi10Mg, the distortion is reduced to zero at a preheating temperature of $250{ }^{\circ} \mathrm{C}$, independent of the sample thickness, as illustrated in [17]. At $400{ }^{\circ} \mathrm{C}$ baseplate temperature, negative deflections of cantilevers are observed for LPBF-processed tool steel 1.2344 (H13), according to the study in [18]. As reported in [19] for stainless steel 1.4540 (PH1) and 1.4404 (316L) LPBF samples, laser shock peening (LSP) effectively changes the residual stress profile from tension to compression. Similarly, high-amplitude compressive residual stresses are introduced into the surface of LPBFprocessed IN 625 samples, after solution treatment at $1070{ }^{\circ} \mathrm{C}$ for $1 \mathrm{~h}$, followed by water quenching and aging at $720^{\circ} \mathrm{C}$ for 18 $\mathrm{h}$, as reported in [20]. By using only the heat treatment approach, the residual stresses of the last-mentioned IN 625 samples are released and close to zero. Barrel finishing (BF), shot peening (SP), ultrasonic shot peening (USP), and ultrasonic impact treatment (UIT) are post processes, which are used for IN 718 LPBF samples in the study of [21]. All the last mentioned post processes result in compressive residual stresses, compared to the LPBF-built specimen. In case of compression, the highest magnitude is achieved with SP, followed by UIT, USP, and BF. In case of LPBF-processed nickel-base alloy 718 , heat treatment at $1066{ }^{\circ} \mathrm{C}$ for $2 \mathrm{~h}$ greatly reduced the residual stresses, as investigated in [10].

To achieve economical LPBF part production combined with high quality in terms of porosity and geometrical accuracy from various materials run in experiments, setup times and efforts for post processing need to be reduced or even avoided. With a second laser beam, a more robust process can be generated. Thus, a second post heating laser source is used in conjunction with a melting laser source in this study, to reduce distortions. This is tested in LPBF processing of CM247LC cantilever samples. A "two bar model" is introduced to explain the generation of residual stresses and their reduction with a multi laser beam offset strategy. Furthermore, re-melting cracks, defects, and microstructure are analyzed in conjunction with the second defocused laser, in case of $200 \mathrm{~W}$.

\section{Experimental procedure}

\subsection{Laser powder bed fusion}

For the LPBF process, a gas atomized CM247LC powder from LPW Technology Ltd with a $d_{50}$ of $40 \mu \mathrm{m}$ has been used. The chemical composition of the CM247LC powder batch can be found in Table 1. To manufacture the LPBF-

Table 1 Chemical composition of CM247LC (wt.\%)

\begin{tabular}{llllll}
\hline $\mathrm{C}$ & $\mathrm{Cr}$ & $\mathrm{Co}$ & $\mathrm{W}$ & $\mathrm{Mo}$ & $\mathrm{Ta}$ \\
0.06 & 8.4 & 9.4 & 9.6 & 0.5 & 3.3 \\
$\mathrm{Al}$ & $\mathrm{Ti}$ & $\mathrm{Hf}$ & $\mathrm{B}$ & $\mathrm{Zr}$ & $\mathrm{Ni}$ \\
5.6 & 0.8 & 1.4 & 0.01 & 0.009 & $\mathrm{Bal}$ \\
\hline
\end{tabular}


Table 2 Used process parameters, defined as reference for the LPBF process, referring to Gerstgrasser et al. [24]

\begin{tabular}{ll}
\hline Laser 1 power: $200 \mathrm{~W}$ & Hatching: $80 \mu \mathrm{m}$ \\
Scan speed: $800 \mathrm{~mm} / \mathrm{s}$ & Layer thickness: $30 \mu \mathrm{m}$ \\
Beam diameter: $90 \mu \mathrm{m}$ & Unidirectional scanning \\
$90^{\circ}$ alternated scan strategy & Energy density: $104.16 \mathrm{~J} / \mathrm{mm}^{3}$ \\
\hline
\end{tabular}

processed cantilevers of CM247LC, a flexible laboratory machine with two water-cooled $200 \mathrm{~W}$ infrared $(1070 \mathrm{~nm})$ fiber lasers and nitrogen atmosphere (oxygen level of $0.5 \%$ ) is used. Detailed information about the LPBF laboratory machine can be found in $[22,23]$. The process parameters from pre-studies, which create dense and crack-free CM247LC samples, as explained in detail in [24], are listed in Table 2, based on the classical definition of the energy density:

$E_{d}=\frac{P}{h \cdot v \cdot t}$

where $E_{d}$ is the energy input or energy density in $\mathrm{J} / \mathrm{mm}^{3}, P$ is the effective laser power in $\mathrm{W}, h$ is the hatch distance in $\mathrm{mm}$, and $v$ and $t$ are the laser scan speed in $\mathrm{mm} / \mathrm{s}$ and layer thickness in $\mathrm{mm}$, respectively.

\subsection{Multi laser beam strategy (offset)}

The multi laser beam offset strategy in LPBF with a second defocused laser beam following the first focus spot on the consolidated side with a lateral and longitudinal offset is adopted from the laser welding field. To reduce the internal stresses, this strategy is there implemented with two additional
Table 3 Pre-test offset parameters with $40 \mathrm{~W}$ for the second laser beam, leading to equations (2) and (3)

\begin{tabular}{lll}
\hline nr. & $x_{\text {off }}(\mu \mathrm{m})$ & $y_{\text {off }}(\mu \mathrm{m})$ \\
\hline 1 & 270 & 240 \\
2 & 270 & 480 \\
3 & 270 & 960 \\
4 & 540 & 240 \\
5 & 540 & 480 \\
6 & 540 & 960 \\
7 & 1080 & 240 \\
8 & 1080 & 480 \\
9 & 1080 & 960 \\
\hline
\end{tabular}

defocused laser beams, as reported in [25]. The schematic top view of the lateral offset strategy with multi laser beams for this LPBF study is shown in Fig. 1 with the additional melt pool dimensions. The small circle in the melt pool image represents the melting laser in the focus plane with a beam diameter of $90 \mu \mathrm{m}$ and a power of $200 \mathrm{~W}$, whereas the great circle stands for the defocused second laser spot with a diameter of $380 \mu \mathrm{m}$ for heating. The offset in $x$-direction $x_{\text {off }}$ is defined as follows, based on geometrical distances in Table 3:

$x_{\text {off }}=(h+10 \mu \mathbf{m}) \cdot n$

where $n$ is an augmentation factor. Based on the geometrical distances in Table 3, the lateral offset in $y$-direction $y_{\text {off }}$ is defined as:

$\boldsymbol{y}_{\text {off }}=\boldsymbol{n} \cdot \boldsymbol{h}$

The values 3, 6, and 12 are used for $n$ to investigate a nonlinear parameter space as pre-test with a laser power of $40 \mathrm{~W}$
Fig. 1 Correctly scaled schematic top view of the offset strategy with corresponding distances, based on equations (2) and (3)

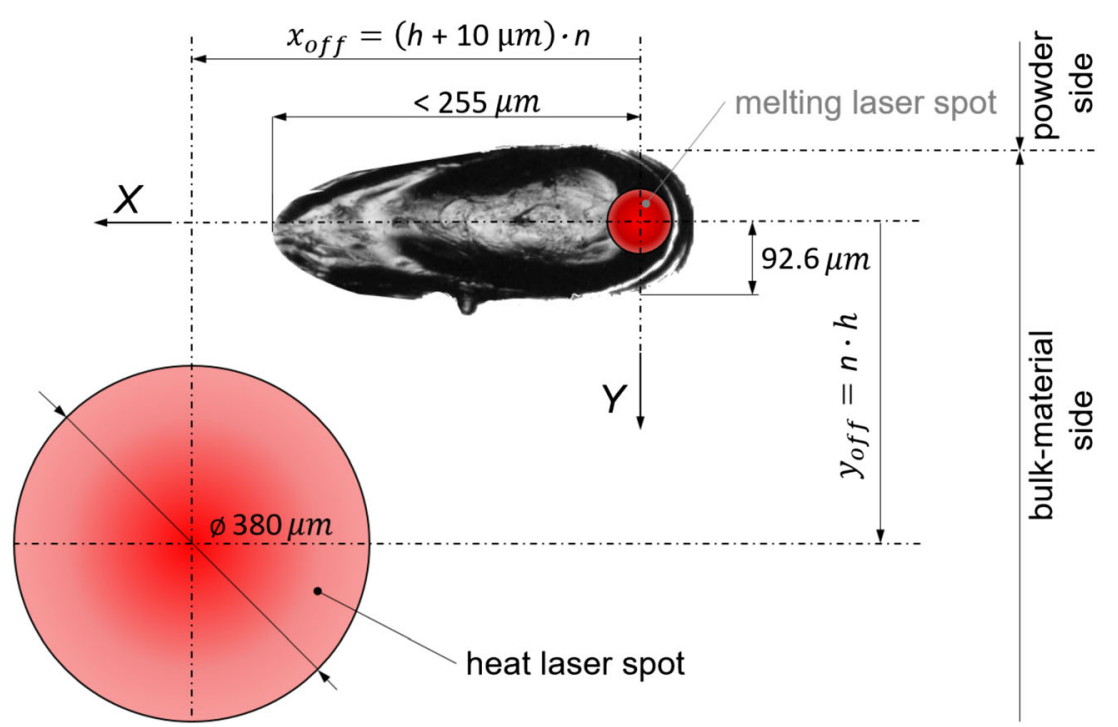


Fig. $2 \Delta h_{\text {base }}, l_{m}$, and cantilever dimensions, which are used to measure the distortion

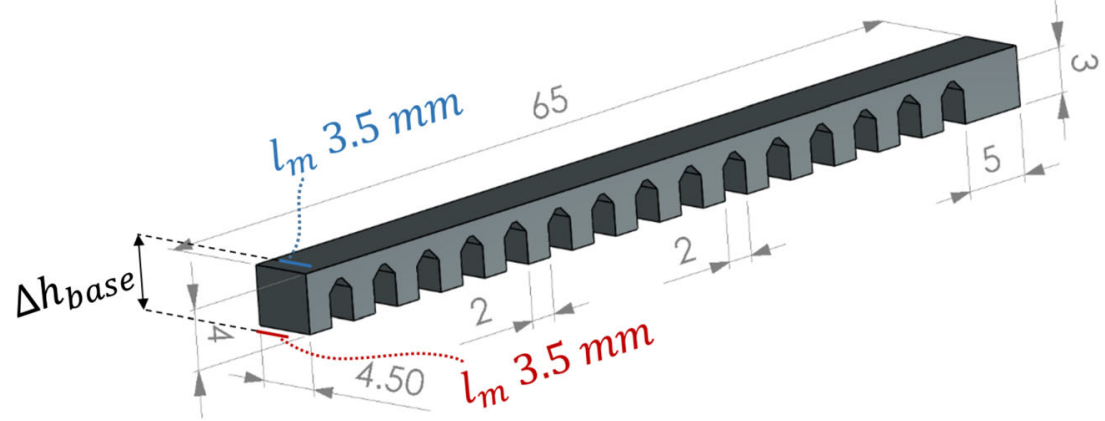

Fig. 3 Cut cantilever with $\Delta h_{c}$

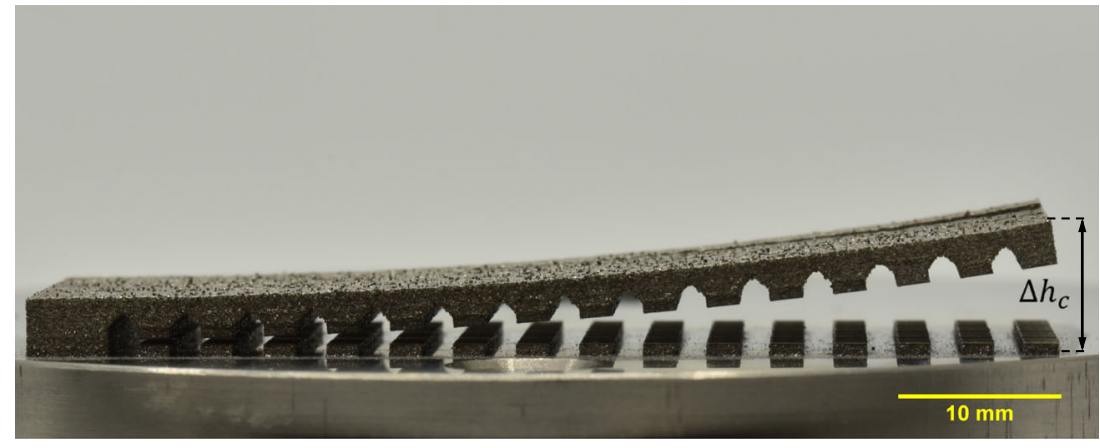

for a second laser beam. The offset values are listed in Table 3 . Finally, the material is processed with the most promising offset parameter and a maximum power of $65 \mathrm{~W}$ for the defocused laser beam, to avoid re-melting the bulk material, which would result in re-melting cracks or defects.

\subsection{Distortion analysis}

In this study, cantilever specimens of CM247LC are manufactured with the LPBF process, since they are widely used to analyze residual stresses or upon partly cutting them off the build platform from one end, the distortions, as reported in $[11,13,17,18,26-34]$. The geometry of the built specimen cantilever is shown in Fig. 2. After building and cooling down, the relative height $\Delta h_{\text {base }}$ from the baseplate to the cantilever is measured with a Keyence digital microscope VHX-5000. To avoid the influence of the edges, the relative height is measured on a line $l_{m}$ with $3.5 \mathrm{~mm}$ measuring length, $1 \mathrm{~mm}$ away from the front edge, and $0.5 \mathrm{~mm}$ from the side edges of the $4.5 \mathrm{~mm}$ wide cantilever. After cutting off, the height of the measuring line is measured again, giving $\Delta h_{c}$, as illustrated in Fig. 3. The average total height difference $\Delta h_{\text {tot }}$ represents the distortion of the cantilever, as follows:

$\Delta h_{\mathrm{tot}}=\frac{1}{l_{m}} \int_{0}^{l_{m}}\left[\Delta h_{c}(\xi)-\Delta h_{\mathrm{base}}(\xi)\right] \mathrm{d} \xi$

The average height $\Delta h_{\text {base }}$ between the baseplate and the uncut cantilever is illustrated in Fig. 2. Including the distortion of the reference, by using its total height difference, the relative distortion can be obtained as follows:

$\boldsymbol{d}_{\mathrm{rel}}=\frac{\Delta \boldsymbol{h}_{\mathrm{tot}}}{\Delta \boldsymbol{h}_{\mathrm{ref}, \mathrm{tot}}}$

where $\Delta h_{\text {ref, tot }}$ is the total height difference of the reference parameter processed cantilever, based on equation
Table 4 Parameters used for remelting crack analysis
Laser 1 power: $200 \mathrm{~W}$

Laser 2 power: $200 \mathrm{~W}$

Beam diameter L1: $90 \mu \mathrm{m}$

Beam diameter L2: $380 \mu \mathrm{m}$

$90^{\circ}$ alternated scan strategy
Scan speed: $1300 \mathrm{~mm} / \mathrm{s}$

Offset $x_{\text {off: }}: 450 \mu \mathrm{m}$

Layer thickness: $30 \mu \mathrm{m}$

Unidirectional scanning

Hatching: $70 \mu \mathrm{m}$ 
Fig. 4 a Re-melting crack and defect analysis $(X Y)$. b EBSD images from the $X Z$ plane

\section{cubic sample analysis}

a)
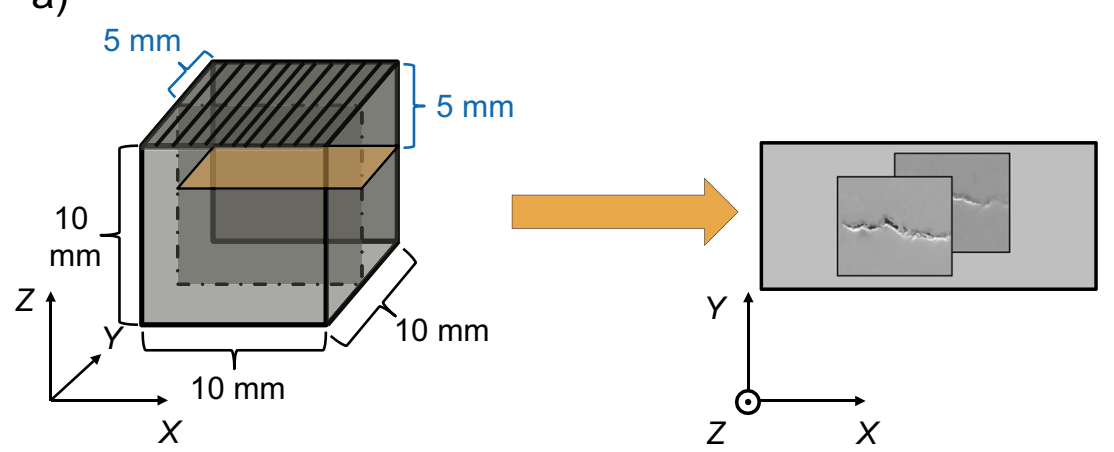

b)

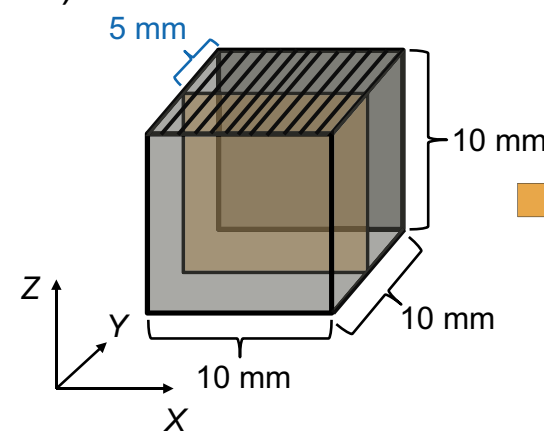

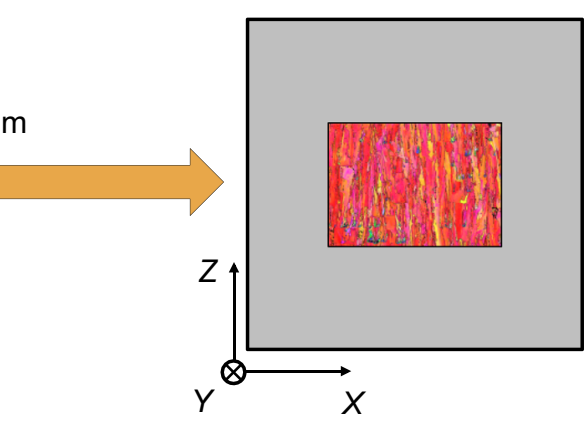

(4). Three cantilevers are built and quantified for each offset parameter.

\subsection{Re-melting cracks}

To demonstrate the influence of the second laser beam on the cracking behavior of CM247LC, the maximum laser power of

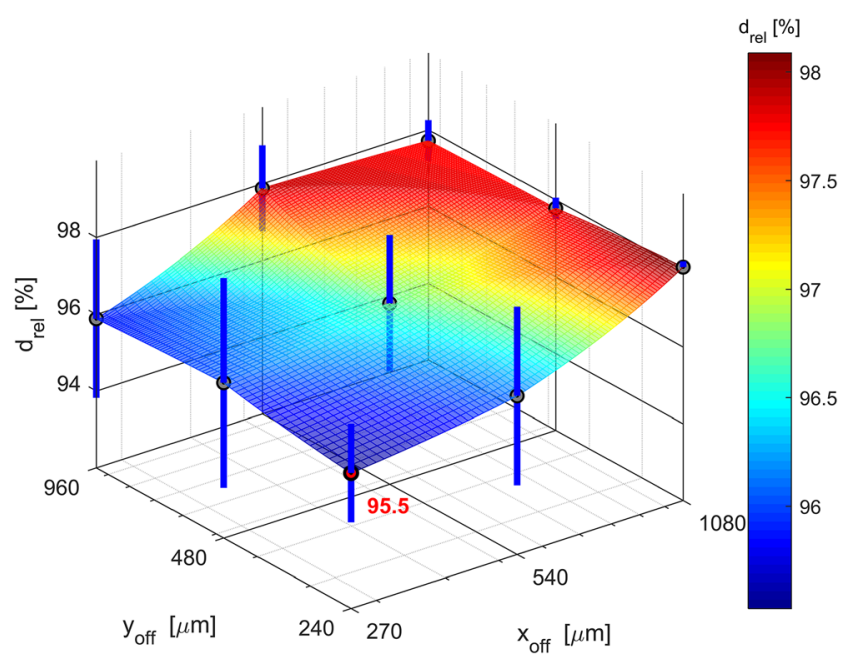

Fig. 5 Relative distortion results from CM247LC cantilevers, manufactured with different offset parameters from Table 3 (logarithmic scale) with a $40 \mathrm{~W}$ laser power (second laser)
$200 \mathrm{~W}$ (from the laser setup) is applied for the second laser, in conjunction with a higher laser scan speed and a $12.5 \%$ reduced hatch distance. This demonstrates that re-melting cracks are independent of a higher laser scan speed and smaller hatching. As mentioned in Section 2.2, exceeding a laser power of $65 \mathrm{~W}$, in case of the defocused second laser beam results in re-melting cracks. To reduce the offset dimensions,

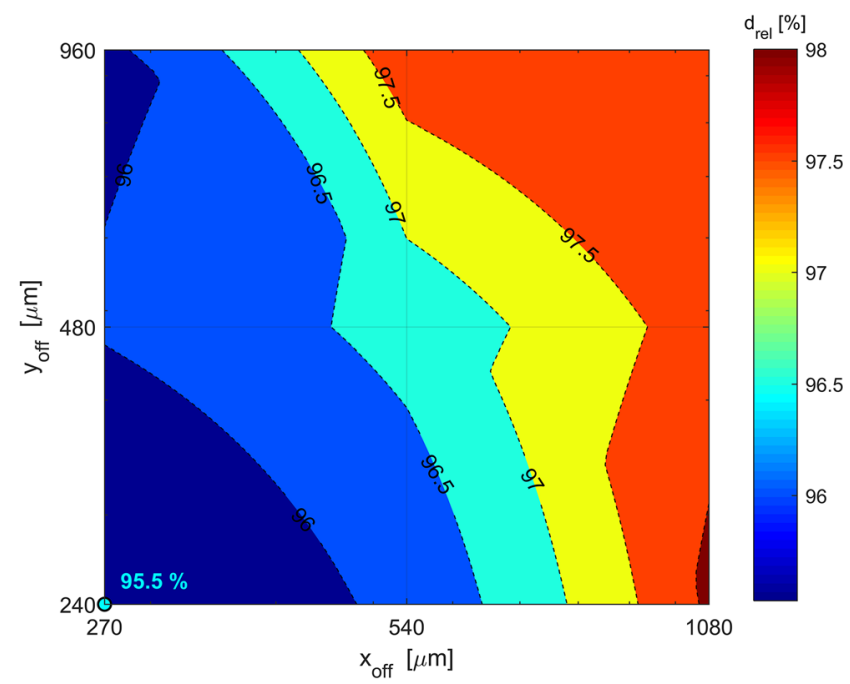

Fig. 6 Relative distortion results (CM247LC) from offset strategy as 2D process map (logarithmic scale) with a $40 \mathrm{~W}$ laser power (second laser) 


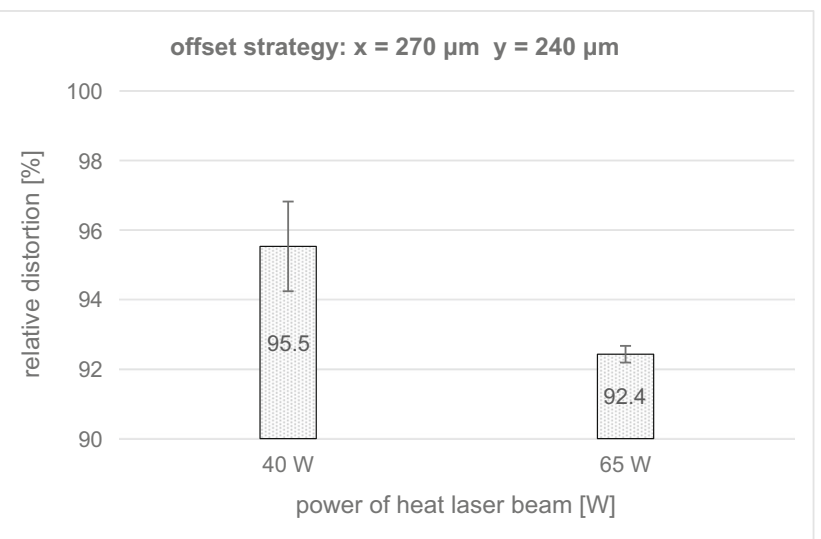

Fig. 7 Further reduction in distortion for CM247LC with increased power up to maximum $65 \mathrm{~W}$ for the heat laser beam (second laser)

only an offset $x_{\text {off }}$ with $450 \mu \mathrm{m}$ is applied. The used process parameters, to realize re-melting cracks in a cubic sample with the dimension of $10 \times 10 \times 10 \mathrm{~mm}^{3}$, are given in Table 4 . The $X Y$ and $X Z$ plane microsections of the cubic sample are prepared by using a Struers Labotom 5 cutting machine, ATM silicon carbide grinding papers (P120 to P2500), and ATM polishing cloths Zeta with water based, poly crystalline diamond suspension $(6,3$, and $1 \mu \mathrm{m})$. The re-melting cracks and corresponding defects are obtained from secondary electron signals (SE) images from the $X Y$ plane, as shown in Fig. 4a. The SE images of re-melting cracks are compared to an SE image with a classical hot crack (solidification crack) from a sample with increased laser beam diameter of $116 \mu \mathrm{m}$ from previous work, which leads to hot cracking, as explained in detail in [24]. The comparison should demonstrate the difference in cracking. Electron backscatter diffraction (EBSD) images are taken from the $X Z$ plane, as illustrated in Fig. 4b. A scanning electron microscope (SEM) FEI Quanta 200F is used, to obtain the SE and EBSD images.

\section{Results and discussion}

The quantified relative distortion values $d_{\text {rel }}$ of the multi laser beam strategy with a power of $40 \mathrm{~W}$, in case of the heat laser beam, are summarized in Fig. 5. A linear interpolation is applied between the nine average data points, illustrated as a relative distortion surface with an appertaining scale bar on the right-hand side, as shown in Fig. 5. The blue error bars on the data points indicate the corresponding experimental standard deviation, based on the measured relative distortions. In average, all offset parameters result in reduced distortion. Compared to the reference, the biggest difference in relative distortion with a value of about $4.5 \%$ is realized by the smallest offsets in $x$ - and $y$-direction, nearly parallel to the melt beam, and marked as red point with the corresponding value in Fig. 5. The relative distortion surface can be expressed as a two-dimensional process map, where the smallest relative distortion value is marked turquoise, as shown in Fig. 6 (lower
Fig. 8 Two bar models, as a simplification to explain the residual stress behavior in LPBF

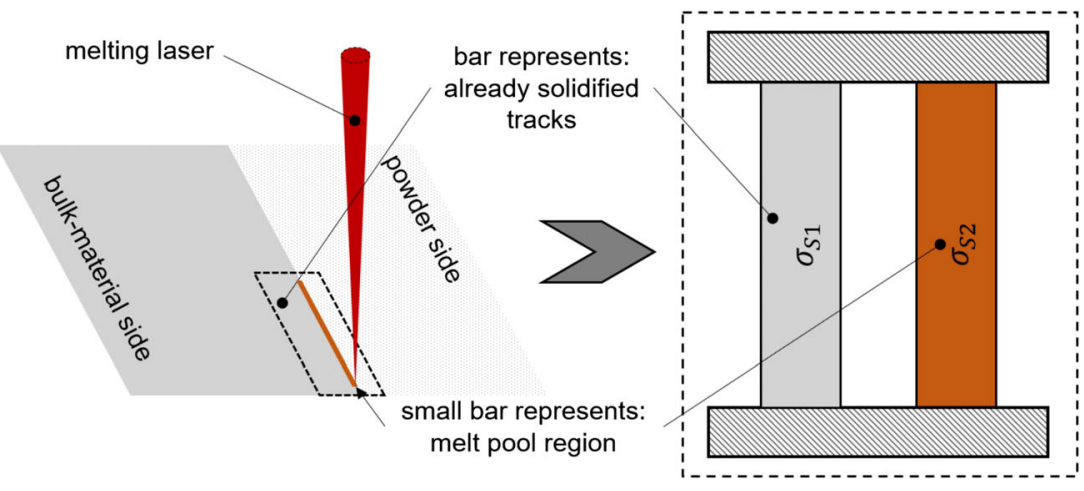

Fig. 9 Two bar models, to explain the stress state in LPBF during and after solidification, without multi laser beam offset strategy

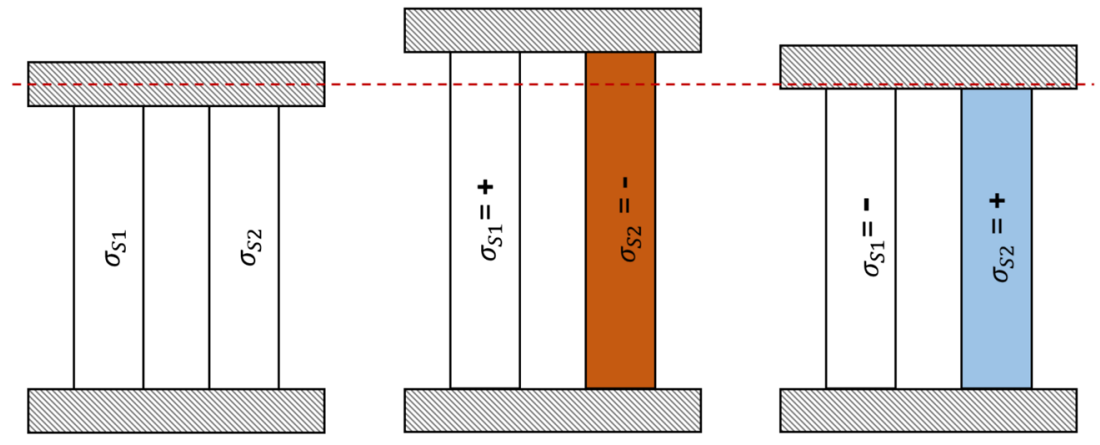


left corner). A further increase in power of the heating laser up to a maximum value of $65 \mathrm{~W}$ with the smallest offsets $x_{\text {off }}$ and $y_{\text {off }}$, as given in section 2.2 , causes a reduction in relative distortion of more than $7.5 \%$, compared to the results achieved with a power of $40 \mathrm{~W}$. This is illustrated in the chart of Fig. 7.
The reduction in distortion with the multi laser beam offset strategy can be explained by the "two bar model," adapted from the "three bar model" from welding, as reported in [35-37]. The "Two bar" model is illustrated in Fig. 8. Both bars have the same geometry. The second bar

Fig. 10 Two different re-melting cracks, in case of $200 \mathrm{~W}$ laser power for the second defocused laser
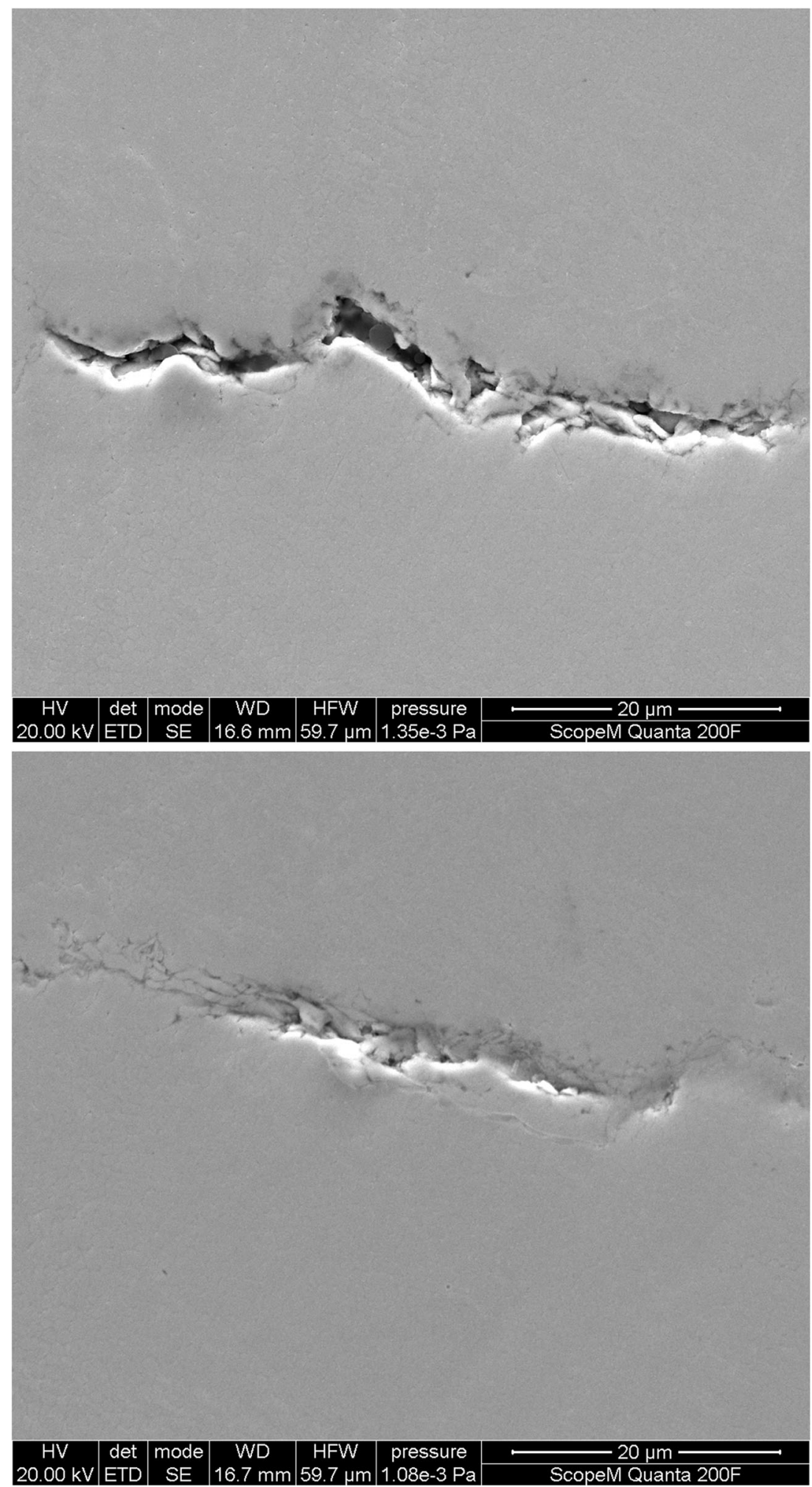
with stress $\sigma_{S 2}$ represents the actual melt pool region, whereas the first bar with $\sigma_{S 1}$ is defined as the already solidified melt tracks. In the model, the two bars have the same length, and their ends are rigidly connected. Before melting, the bars have equal environmental temperature states, as shown in Fig. 9 on the left-hand side with white bars. Due to heating up with the melt laser beam, the melt pool region bar (second bar) expands and pulls along the first bar, which responds to the thermal expansion of the second bar. The stress $\sigma_{S 1}$ in the first bar has the same amplitude as the stress $\sigma_{S 2}$, just with the opposite sign:

$\sigma_{S 1}=-\sigma_{S 2}$

Hence, the first bar is in tension, whereas the second one is under compression, as illustrated in Fig. 9 (central image) with the orange colored bar. The length of the two bars has to be equal at any time, due to the defined rigid connection, which can be expressed as follows, according to the studies of [36, 37]:

$\frac{\sigma_{S 1}}{E\left(T_{0}\right)}=\frac{\sigma_{S 2}}{E(T)}+\alpha \cdot\left(T-T_{0}\right)$

where $T_{0}$ is the environmental temperature in this case, $T$ is the elevated temperature, $E(T)$ is the temperature dependent Young's modulus, and $\alpha$ is the coefficient of thermal expansion. Including the assumed equation (6), equation (7) can be expressed as follows, with respect to the stress in the second bar (assuming transformation of total thermal strain into plastic strain):

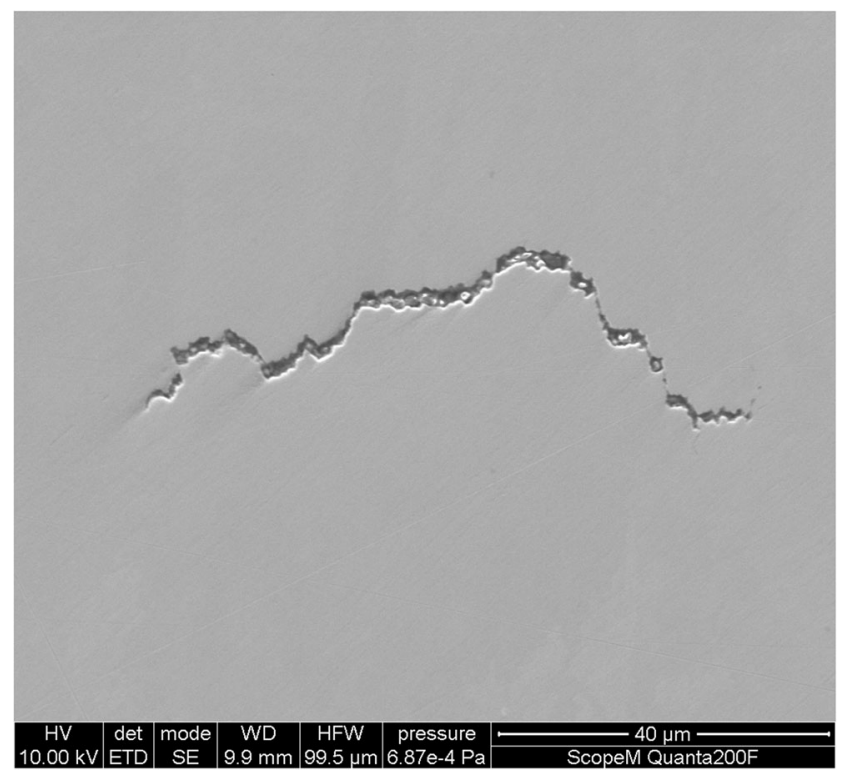

Fig. 11 Classical hot crack (solidification crack) from a sample with an increased laser beam diameter of approximately $116 \mu \mathrm{m}$, which leads to hot cracking, as explained in detail in [24]

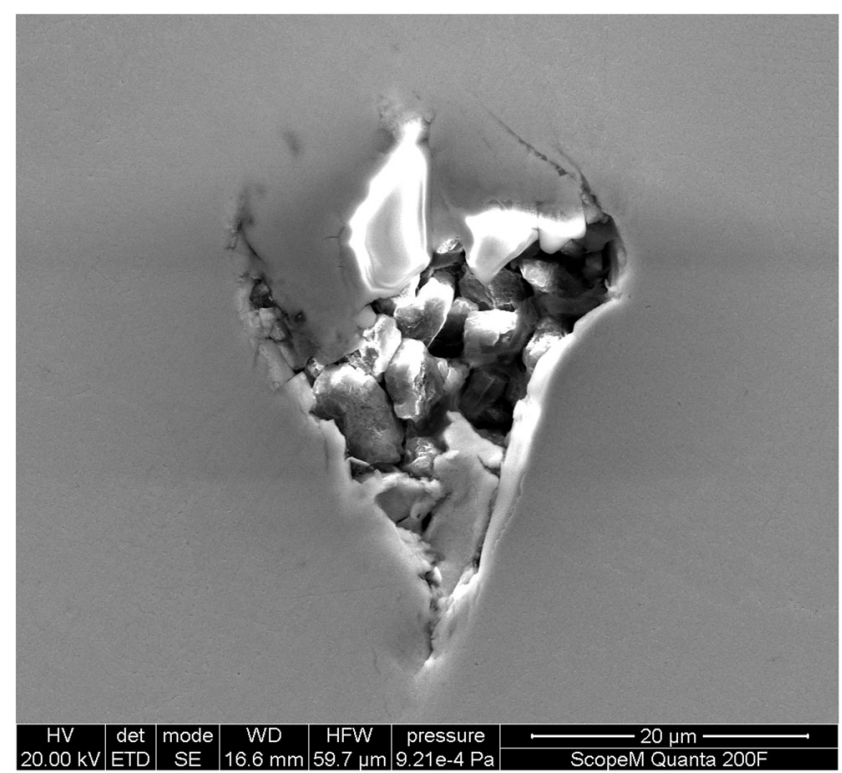

Fig. 12 New kind of defect, which has a different morphology, compared to a classical pore

$\sigma_{S 2}=-\alpha \cdot\left(\boldsymbol{T}-\boldsymbol{T}_{\mathbf{0}}\right) \cdot \frac{\boldsymbol{E}\left(\boldsymbol{T}_{\mathbf{0}}\right)}{\left(\mathbf{1}+\left[\boldsymbol{E}\left(\boldsymbol{T}_{\mathbf{0}}\right) / \boldsymbol{E}(\boldsymbol{T})\right]\right)}$

Since the temperature is quite high in the vicinity of the melting pool, the yield strength of the material drops, and the second bar deforms plastically, as reported in [35]. The second bar pushes the first bar into a compression state, whereas the second bar is now in tension, as illustrated in Fig. 9 on the righthand side. Using the multi laser beam offset strategy, realized by the second heat laser, the environmental temperature increases, which reduces the temperature difference $\left(T-T_{0}\right)$ and the Young's modulus dependent factor in equation (8), since $E\left(T_{0}\right)$ is getting closer to $E(T)$. Reaching a lower stress $\sigma_{S 2}$ in

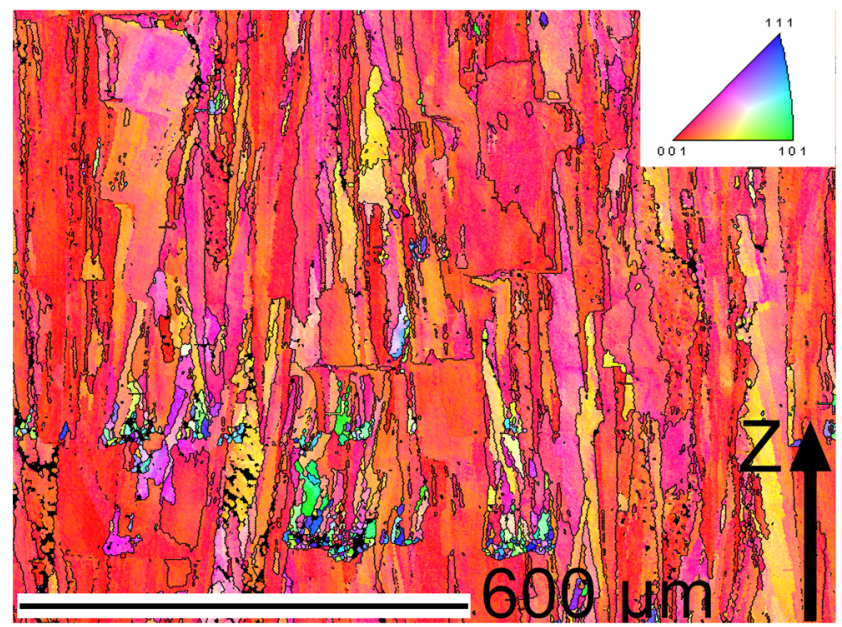

Fig. 13 EBSD IPF with respect to the $Z$-axis for LPBF-processed CM247LC with $200 \mathrm{~W}$ for the second offset laser 


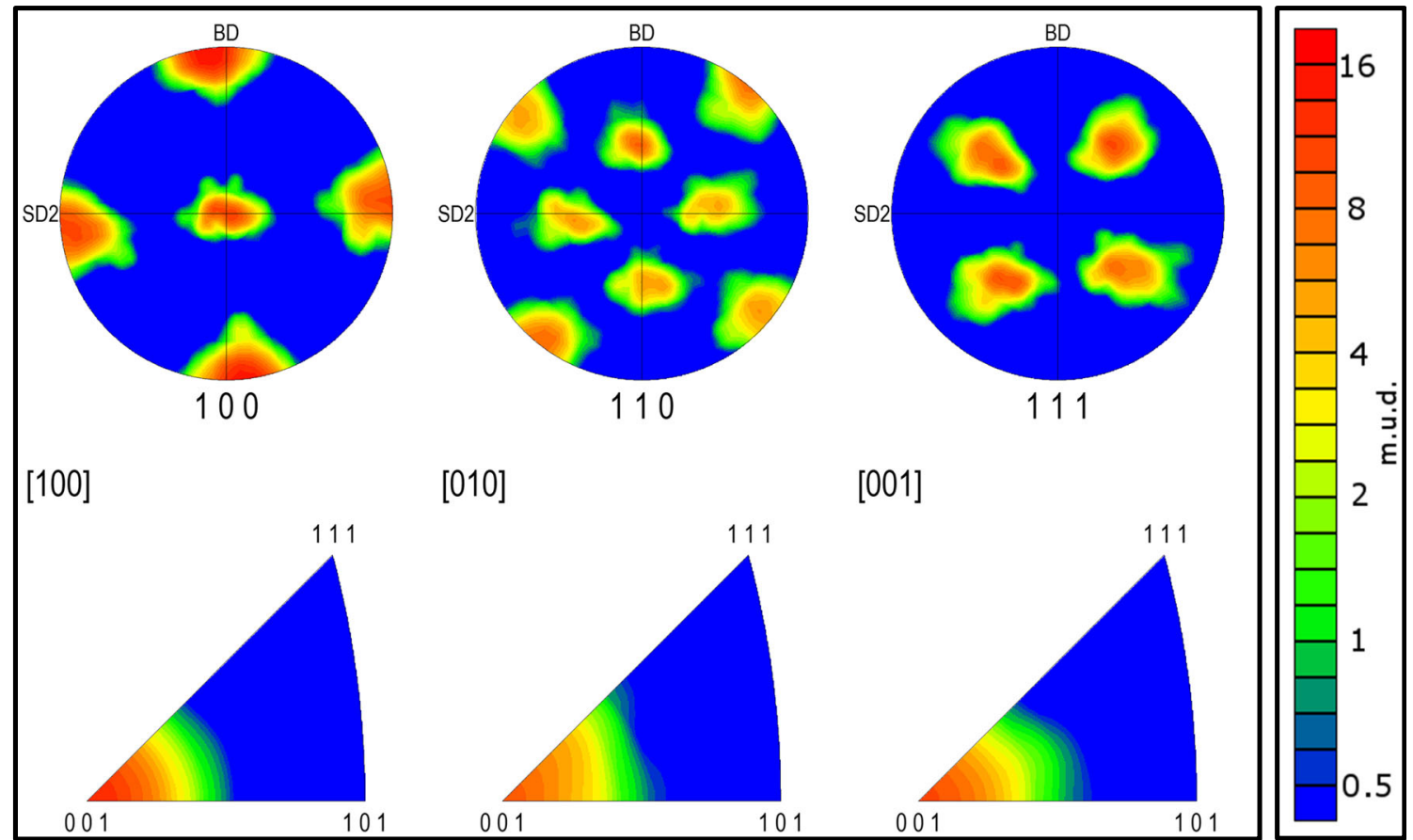

Fig. 14 Pole figures 100,110, and 111 with crystal preferred orientations and inverse pole figures (IPF) with respect to the $Z$-axis (100), $X$-axis ( 010 ), and $Y$-axis (001), in case of $200 \mathrm{~W}$ for the second offset laser

the two bar model leads to less distortion and residual stress in the LPBF part, which can be seen more clearly in the expression of equation (7), regarding the elongation.

The SE SEM images in Fig. 10, obtained from $200 \mathrm{~W}$ power in case of the second laser, show different kind of cracks, named "re-melting cracks." They tend to have a more "chaotic" morphology, compared to the classical solidification or hot cracks, as shown in Fig. 11 and analyzed in [24]. Furthermore, a new kind of defect is identified, which cannot be classified as a typical pore, due to its morphology, as shown in Fig. 12. In Fig. 13, the inverse pole figure (IPF) map for LPBF-processed CM247LC with respect to the $Z$-axis is illustrated, based on the process parameters in Table 4. Not only the typical fine elongated grains with a strong texture dominated by the preferential alignment of $<001>$ along the $Z$-axis are discovered, as already reported by $[38,39]$, but also regions of rather fine and heterogeneously distributed grains. The still preferred crystallographic orientation of $<001>\{100\}$ can be directly obtained from the pole figures and inverse pole figures, as shown in Fig. 14.

\section{Conclusion}

The influence of different multi laser beam offset strategies on the distortion of LPBF-processed CM247LC cantilever is investigated. Since pores and cracks act like residual stress annihilators, process parameters, which lead to dense and crackfree samples, are set as reference and used for further distortion investigations and analysis. Comparing the nine different offset parameters to the reference, the following statements can be made:

- All nine offset parameters in conjunction with the second heat laser beam result in reduced part distortion.

- The multi laser beam offset strategy is an in situ process approach for direct residual stress reduction, without postprocessing, any build chamber heating, or changing the alloy composition. During LPBF, thermal induced residual stresses are one of the critical aspects, especially when it comes to thin walls. A second heat laser beam could lead to new research opportunities for residual stress reduction in critical elements.

- The multi laser beam offset strategy with a defocused beam diameter of $380 \mu \mathrm{m}$ for the second heat laser and a maximum power of $65 \mathrm{~W}$, to avoid re-melting cracks, reduces the relative distortion more than $7.5 \%$.

- The presented "two bar model" represents a simple approach to explain the residual stress behavior and reduction via multi laser beam offset strategy in a vivid and physical way.

- Further investigations with larger beam diameters and increased laser powers are suggested, because then the heating of the environment is stronger and the revealed effects might increase, without re-melting.

- In case of an industrial application, cylindrical transverse mode patterns in conjunction with a single melting laser beam during LPBF-processing could be used instead of a 
second heat laser beam. This opens further research fields in case of residual stress reduction during LPBF with a single laser beam. Generally, the current study demonstrates the potential of local environment heating during LPBF processing.

Furthermore, re-melting defects and microstructure are analyzed, in case of the second defocused offset laser with a laser power of $200 \mathrm{~W}$, an increased laser scan velocity, and a reduced hatch distance. Re-melting cracks tend to have a more "chaotic" morphology, compared to classical hot cracks (solidification cracks). Secondary electron signal (SE) images from the $X Y$ plane were taken for the crack comparison. A new kind of defect, which has a different morphology compared to classical pores, has been identified, based on SEM image. In case of the microstructure, not only elongated grains with a strong texture but also regions of rather fine and heterogeneously distributed grains are identified.

Acknowledgements The authors would like to thank the Swiss Innovation Agency Innosuisse for financial support in the frame of project 25357.2 PFNM-NM, Moritz Wiessner for wire-EDM cutting, Karsten Kunze, for the SEM support at ScopeM, Jordan Borinelli for the microscopic support, and Kiran Michael for proofreading.

Author contribution Marcel Gerstgrasser: conceptualization, methodology, investigation, writing - original draft, formal analysis, data curation, visualization

Michael Cloots: project administration, conceptualization

Josef Stirnimann: project administration

Konrad Wegener: supervision, writing - review and editing

Funding Open Access funding provided by ETH Zurich. This study was funded by the Swiss Innovation Agency Innosuisse in the frame of project 25357.2 PFNM-NM.

Data availability Data will be made available on request.

\section{Declarations}

Ethics approval Work was conducted ethically with no human test subjects.

Consent to participate This research did not involve human subjects.

Consent for publication All authors are interested in publishing the work.

Conflict of interest The authors declare no competing interests.

Open Access This article is licensed under a Creative Commons Attribution 4.0 International License, which permits use, sharing, adaptation, distribution and reproduction in any medium or format, as long as you give appropriate credit to the original author(s) and the source, provide a link to the Creative Commons licence, and indicate if changes were made. The images or other third party material in this article are included in the article's Creative Commons licence, unless indicated otherwise in a credit line to the material. If material is not included in the article's Creative Commons licence and your intended use is not permitted by statutory regulation or exceeds the permitted use, you will need to obtain permission directly from the copyright holder. To view a copy of this licence, visit http://creativecommons.org/licenses/by/4.0/.

\section{References}

1. Santos EC, Shiomi M, Osakada K, Laoui T (2006) Rapid manufacturing of metal components by laser forming. Int J Mach Tools Manuf 46:1459-1468

2. Prasad NE, Wanhill R (2017) Aerospace materials and material technologies Volume 2: Springer

3. Carter LN, Attallah MM, Reed RC (2012) Laser powder bed fabrication of nickel-base superalloys: influence of parameters; characterisation, quantification and mitigation of cracking. Superalloys 2012:577-586

4. Mercelis P, Kruth JP (2006) Residual stresses in selective laser sintering and selective laser melting. Rapid prototyping journal

5. Vora P, Mumtaz K, Todd I, Hopkinson N (2015) AlSi12 in-situ alloy formation and residual stress reduction using anchorless selective laser melting. Additive Manufacturing 7:12-19

6. Vora P, Martinez R, Hopkinson N, Todd I, Mumtaz K (2017) Customised alloy blends for in-situ Al339 alloy formation using anchorless selective laser melting. Technologies. 5:24

7. Lu Y, Wu S, Gan Y, Huang T, Yang C, Junjie L et al (2015) Study on the microstructure, mechanical property and residual stress of SLM Inconel-718 alloy manufactured by differing island scanning strategy. Opt Laser Technol 75:197-206

8. Bagg SD, Sochalski-Kolbus LM, Bunn JR (2016) The effect of laser scan strategy on distortion and residual stresses of arches made with selective laser melting

9. Ali H, Ghadbeigi H, Mumtaz K (2018) Effect of scanning strategies on residual stress and mechanical properties of Selective Laser Melted Ti6A14V. Mater Sci Eng A 712:175-187

10. Goel S, Neikter M, Capek J, Polatidis E, Colliander MH, Joshi S et al (2020) Residual stress determination by neutron diffraction in powder bed fusion-built Alloy 718: influence of process parameters and post-treatment. Mater Des 195:109045

11. Mugwagwa L, Dimitrov D, Matope S, Yadroitsev I (2018) Influence of process parameters on residual stress related distortions in selective laser melting. Procedia Manufacturing 21:92-99

12. Simson T, Emmel A, Dwars A, Böhm J (2017) Residual stress measurements on AISI 316L samples manufactured by selective laser melting. Additive Manufacturing 17:183-189

13. Yakout M, Elbestawi M, Veldhuis SC (2019) Density and mechanical properties in selective laser melting of Invar 36 and stainless steel 316L. J Mater Process Technol 266:397-420

14. Malý M, Höller C, Skalon M, Meier B, Koutný D, Pichler R et al (2019) Effect of process parameters and high-temperature preheating on residual stress and relative density of Ti6Al4V processed by selective laser melting. Materials. 12:930

15. Bartlett JL, Li X (2019) An overview of residual stresses in metal powder bed fusion. Additive Manufacturing 27:131-149

16. Ali H, Ma L, Ghadbeigi H, Mumtaz K (2017) In-situ residual stress reduction, martensitic decomposition and mechanical properties enhancement through high temperature powder bed pre-heating of Selective Laser Melted Ti6Al4V. Mater Sci Eng A 695:211-220

17. Buchbinder D, Meiners W, Pirch N, Wissenbach K, Schrage J (2014) Investigation on reducing distortion by preheating during manufacture of aluminum components using selective laser melting. Journal of laser applications 26:012004 
18. Zumofen L, Beck C, Kirchheim A, Dennig H.-J (2017) Quality related effects of the preheating temperature on laser melted high carbon content steels. International Conference on Additive Manufacturing in Products and Applications: Springer. p. 210-9

19. Kalentics N, Boillat E, Peyre P, Ćirić-Kostić S, Bogojević N, Logé RE (2017) Tailoring residual stress profile of selective laser melted parts by laser shock peening. Additive Manufacturing 16:90-97

20. Chen L, Sun Y, Li L, Ren X (2020) Microstructural evolution and mechanical properties of selective laser melted a nickel-based superalloy after post treatment. Mater Sci Eng A 792:139649

21. Lesyk DA, Martinez S, Mordyuk BN, Dzhemelinskyi VV, Lamikiz A, Prokopenko GI (2020) Post-processing of the Inconel 718 alloy parts fabricated by selective laser melting: effects of mechanical surface treatments on surface topography, porosity, hardness and residual stress. Surf Coat Technol 381:125136

22. Heeling T, Wegener K (2018) The effect of multi-beam strategies on selective laser melting of stainless steel $316 \mathrm{~L}$. Additive Manufacturing 22:334-342

23. Heeling T (2018) Synchronized two-beam strategies for selective laser melting: ETH Zurich

24. Gerstgrasser M, Cloots M, Stirnimann J, Wegener K (2021) Focus shift analysis, to manufacture dense and crack-free SLM-processed CM247LC samples. J Mater Process Technol 289:12

25. Tölle F, Gumenyuk A, Backhaus A, Olschok S, Rethmeier M, Reisgen U (2012) Welding residual stress reduction by scanning of a defocused beam. J Mater Process Technol 212:19-26

26. Afazov S, Denmark WA, Toralles BL, Holloway A, Yaghi A (2017) Distortion prediction and compensation in selective laser melting. Additive Manufacturing 17:15-22

27. Li C, Liu J, Guo Y (2016) Efficient multiscale prediction of cantilever distortion by selective laser melting. Proceeding of SFF Symposium. p. 236-46

28. Li C, Liu J, Fang X, Guo Y (2017) Efficient predictive model of part distortion and residual stress in selective laser melting. Additive Manufacturing 17:157-168

29. Zaeh MF, Branner G (2010) Investigations on residual stresses and deformations in selective laser melting. Prod Eng 4:35-45

30. Neugebauer F, Keller N, Ploshikhin V, Feuerhahn F, Köhler H (2014) Multi scale FEM simulation for distortion calculation in additive manufacturing of hardening stainless steel. International
Workshop on Thermal Forming and Welding Distortion, Bremen, Germany

31. Papadakis L, Loizou A, Risse J, Schrage J (2014) Numerical computation of component shape distortion manufactured by selective laser melting. Procedia Cirp 18:90-95

32. Yang Y, Allen M, London T, Oancea V (2019) Residual strain predictions for a powder bed fusion Inconel 625 single cantilever part. Integrating Materials and Manufacturing Innovation 8:294 304

33. Ahmad B, van der Veen SO, Fitzpatrick ME, Guo H (2018) Residual stress evaluation in selective-laser-melting additively manufactured titanium (Ti-6Al-4V) and inconel 718 using the contour method and numerical simulation. Additive Manufacturing 22: 571-582

34. Yadroitsava I, Grewar S, Hattingh D, Yadroitsev I (2015) Residual stress in SLM Ti6Al4V alloy specimens. Materials Science Forum: Trans Tech Publ. p. 305-10

35. Michaleris P (2011) Introduction to welding residual stress and distortion. Minimization of Welding Distortion and Buckling: Elsevier. p. 3-22

36. Schnubel D (2012) Laser heating as approach to retard fatigue crack growth in aircraft aluminium structures: Technische Universität Hamburg

37. Masubuchi K (1980) Analysis of welded structures: residual stresses, distortion, and their consequences (International Series on Materials Science and Technology). Pergamon Press Oxford and New York

38. Carter LN, Martin C, Withers PJ, Attallah MM (2014) The influence of the laser scan strategy on grain structure and cracking behaviour in SLM powder-bed fabricated nickel superalloy. J Alloys Compd 615:338-347

39. Muñoz-Moreno R, Divya V, Driver S, Messé O, Illston T, Baker S et al (2016) Effect of heat treatment on the microstructure, texture and elastic anisotropy of the nickel-based superalloy CM247LC processed by selective laser melting. Mater Sci Eng A 674:529-539

Publisher's note Springer Nature remains neutral with regard to jurisdictional claims in published maps and institutional affiliations. 